\title{
Impact of Motivation on Organizational Citizenship Behaviors in Nepalese Non-Life Insurance Companies
}

\author{
Jitendra Prasad Upadhyay, Ph.D. \\ Associate Professor, Nepal Commerce Campus, T.U. \\ Pitri Raj Adhikari \\ Lecturer, Shanker Dev Campus, T.U.
}

\begin{abstract}
This paper attempts to examine the impact of motivation on organizational citizenship behavior in Nepalese non-life insurance companies. Data are collected through a structured questionnaire from 325 respondents of 20 non-life insurance companies of Kathmandu valley. Descriptive and causal-comparative research design are used to achieve the objectives and descriptive as well as multiple regression models have been used to analyze the data.Organizational citizen behavior is the dependent variable and authority, autonomy, promotion, salary, recognition, career opportunity are independent variables. It is observed that all independent variables have a positive and significant relationship with organizational citizenship behavior.
\end{abstract}

Keywords: Organizational citizen behavior, Authority, Autonomy, Promotion, Salary, Recognition, Career opportunity

Paper Type: Research Paper

\section{Introduction}

Organizational citizenship behavior (OCB) is one of the researchable issues for practitioners and researchers for the last few decades. Prior research has linked organizational citizenship behavior with different predictors. Among them, motivation is one of the important predictors.Chiang and Hsieh (2012) stated that OCB helps in enhancing productivity, facilitatesthe organization to compete regardless of limited resources, helps in better coordination among employees, helpsan organization to overcome employees turnover, enhances organization adaptability, increases profitability and customer satisfaction. OCB is a job behavior which is neither compulsory on the part of the individual nor the part of the formal reward system of organizations, yet it contributes to the overall effectiveness of the organizational (Bateman \&Organ, 1983).OCB increases performance quality of employees by influencing intra-organizational factors such as organizational atmosphere, morale improvement, increase of organizational commitment, job satisfaction, reduction of turnover on tents and reduction of absences and detrimental job behavior and by influencing extra- organizational factors such as job satisfaction, services quality and customer loyalty (Castro, et al. 2004). According to Hieu and Cham (2020), there is the impact of motivation factors on commitment factors. Similarly, Meyer et al. (2002) revealed that the influence of normative commitment on organizational success has received less attention because of its relatively weaker influence than other aspects of commitment, however, Kim et al. (2019) observed that normative commitment significantly 
Issue 1 May/June 2020

influenced employee consideration, civic virtue, and conscientiousness.

To support organizational goals and values employee recognition, the acknowledgement of an individual or team's behavior, is important and if employees and their work are valued, their satisfaction and productivity rise and they are motivated to maintain or improve their good work. Sharma and Agrawal (2014) found a positive and significant relationship between reward and recognition with the performance of employees. Likewise, Sinnappanand Amulraj (2014) revealed that recognition and reward have a significant relationship with all the four dimensions of OCB (Altruism, conscientiousness, teambuilding and loyalty). Employees are motivated when if they feel their career opportunity is good and they do better to achieve organizational goal. Pujiwati (2016)concluded that performance assessment has a positive and significant impact on career development. Similarly, Nawayand Haris (2017) stated that career development, perception of organizational justice, and job satisfaction had a direct effect on employees' OCB. Therefore, they recommended improving employees' OCB through career development, perception of organizational justice and job satisfaction. Likewise, Biswakarma (2016) revealed that the organizational career growth dimensions negatively related to employees' turnover intentions and also focused that promotion speed and remuneration growth are the foremost factors which havea direct high impact on employees' turnover intentions, followed by career growth progress. Furthermore,Nepal (2016) examinedthe positive relationship between career development and human resource planning.

Researchers have focused autonomy as a component for OCB. Gagne(2003) revealed that autonomy orientation was strongly related to engagement in prosaic behavior, while autonomy support was modestly related. Similarly, Newburrsy et al. (2008) indicated that autonomy increases employees' willingness to do whatever it takes (including citizenship) to accomplish the task. Employees in highly autonomous jobs dictate their job rather than being instructed by their bosses. Likewise, Nam and Yoo (2016) found that the effectiveness of the autonomy-supportive motivating style is partly due to its association with volitional deference to authority. Furthermore, promotion, an important motivational factor, has a positive relationship with satisfaction (Yaseen, 2013).Further, encouraging ethical leadership and leader-member exchange within organizations supports OCB among the employees (Arshad et al., 2020). Therefore, the research on the impact of motivational factors on OCB is of greater importance. Moreover, research has been done concerning the issue of the impact of motivational factors on OCB in western context; however, there are some research has been done in the context of Nepal. Hence, this paper attempts to examine the linkage between motivational factors and OCB of non-life insurance companies in Nepalese context. The next section of this paper is concerned with the research hypotheses.

\section{Research Hypotheses}

This study has set the following alternative hypotheses:

$\mathrm{H} 1$ : There is a positive relationship between recognition and organizational citizenship behavior

$\mathrm{H} 2$ : There is a positive relationship between salary and organizational citizenship behavior

H3: There is a positive relationship between promotion and organizational citizenship behavior.

H4: There is a positive relationship between autonomy with organizational citizenship behavior.

H5: There is a positive relationship between authority and organizational citizenship behavior.

H6: There is a positive relationship between career opportunity and organizational citizenship behavior.

\section{Methods}

This study has used descriptive research design for facts finding and to identify information about the impact of motivation on organizational citizenship behavior in Nepalese non-life insurance companiesand also has adopted the causal-comparative research design to establish the cause and effect relationship of authority, autonomy, promotion, salary, recognition andcareer opportunity on OCB. Self-administered structured questionnaires were distributed to 400 respondents (20 respondents from each 20 non-life 
insurance companies), however, only 325 usable questionnaires are collected (the response rate is 81.25 per cent).The questionnaire is divided into two sections where the first section is related to the basic information of the respondents and next section is concerned with five-point Likert type questions about the quality variables that affect organization citizenship behavior which scale ranges from 1 (Strongly agree) to 5 (Strongly disagree).Multiple regression models are used in this paper that is presented as:

$$
\mathrm{OCB}=\alpha+\beta \_1 \mathrm{~A}+\beta \_2 \mathrm{AU}+\beta \_3 \mathrm{~S}+\beta \_4 \mathrm{P}+\beta \_5 \mathrm{R}+\beta \_6 \mathrm{CO}+\varepsilon
$$

Where, $O C B=$ Organizational citizenship behavior, $A=$ Authority, $A U=$ Autonomy, $S=$ Salary, $P=$ Promotion, $R=$ Recognition, $C O=$ Career opportunity, $\mathcal{E}=$ error term, $\alpha=$ intercept, $\beta 1, \beta \_2, \beta \_3, \beta \_(4)$ and $\beta 5$ are the beta coefficient of explanatory variables to be estimated.

\section{Limitations}

This study aims to widening the understandings and narrowing the knowledge gap about the impact of motivation on organizational citizenship behavior in Nepalese non-life insurance companies. Despite sincere efforts made for arriving at the meaningful conclusion from the study, some limitations deserve consideration to obtain a reliable interpretation of the results. Limitations of this paper are summarized as follows:

- This paper predominately based on the primary source of data regarding the impact of motivation on organizational citizenship behavior in Nepalese non-life insurance companies. Hence, the reliability of the findings of this paper depends on the degree of accuracy of the information provided by the respondents.

- The sample size in this study is only from the non-life insurance companies in Kathmandu valley. The survey is conducted within limited respondents of non-life insurance companies.

- It is based on the assumption of the linear regression between the dependent and independent variables. The paper excluded the non-linear regression assumptions.

- This study is based on non-life insurance companies in Kathmandu valley. So, this study contains a small area under the study.

- The data has been gathered using a questionnaire method only.

\section{Data Analysis}

\section{Descriptive analysis}

The mean of authority ranges from a minimum value of 1.68 to a maximum value of 2.47 and a weighted average is 2.02 that reveals that authority leads to motivation on organizational citizenship behavior on non-life insurance companies. Similarly, the mean value of autonomy ranges from a minimum value of 1.79 to a maximum value of 2.11 and a weighted average is 1.99 which states that autonomy also leads to motivation on OCB. Likewise, the mean value of salary ranges from a minimum value of 1.78 to a maximum value of 2.11 and a weighted average is 1.91 that indicates that employees are satisfied by the impact of motivation on OCB by salary. Additionally, the mean value of promotion as a motivational factor ranges from 1.79 to 1.91 and a weighted average is 1.85 that shows employees are satisfied by the motivation on OCB by promotion.

Furthermore, the mean value of recognition ranges from a minimum value of 1.73 to a maximum value of 1.93 and weighted is 1.83 which concludes that employees are motivated as they are recognized. Similarly, the mean value of career opportunity ranges from a minimum value of 1.73 to a maximum value of 1.93 and a weighted average is 1.84 that indicates employees are motivated they get career opportunities. Moreover, the mean value of organization citizenship behavior ranges from a minimum value of 1.74 to maximum value of 1.92 and a weighted average is 1.83 that reveals employees are motivated on organizational citizenship behavior on non-life insurance companies of Nepal. 
Issue 1 May/June 2020

\section{Correlation analysis}

Table 1

Correlation matrix

\begin{tabular}{llllllllll}
\hline Variables & Mean & SD & A & AU & S & P & R & CO & OCB \\
\hline $\mathrm{A}$ & 2.02 & 0.484 & 1.000 & & & & & & \\
$\mathrm{AU}$ & 1.99 & 0.456 & 0.357 & 1.000 & & & & & \\
$\mathrm{~S}$ & 1.91 & 0.472 & 0.427 & 0.429 & 1.000 & & & & \\
$\mathrm{P}$ & 1.85 & 0.443 & 0.361 & 0.361 & 0.463 & 1.000 & & & \\
$\mathrm{R}$ & 1.83 & 0.389 & 0.347 & 0.411 & 0.407 & 0.497 & 1.000 & & \\
$\mathrm{CO}$ & 1.84 & 0.419 & 0.338 & 0.329 & 0.311 & 0.362 & 0.374 & 1.000 & \\
$\mathrm{OCB}$ & 1.83 & 0.348 & 0.368 & 0.288 & 0.321 & 0.343 & 0.359 & 0.351 & 1.000 \\
\hline
\end{tabular}

The result shows that all independent variables are positively correlated to motivation on organizational citizenship behavior of non-life insurance companies that reveals higher the level of authority, higher would be the employee motivated, higher in autonomy, higher would be the employees motivated, incrementssalary increases employees' motivation, promotion motivates the employees, increases in recognition helps to increase employeesmotivation, and increase in career opportunities motivates the employees.

\section{Regression analysis}

Table 2

Regression Results

This table presents the regression results using the regression model: $O C B=\alpha+\beta \_1 A+\beta \_2 A U+\beta \_3$ $S+\beta \_4 P+\beta \_5 R+\beta \_6 C O+\mathcal{E}$, where, $O C B=$ Organizational citizenship behavior, A= Authority, $A U=$ Autonomy, $S=$ Salary, $P=$ Promotion, $R=$ Recognition, $C O=$ Career opportunity, $\varepsilon=$ error term, $\alpha=$ intercept, $\beta 1, \beta \_2, \beta \_3, \beta \_(4), \beta 5$ and $\beta 6$ are the beta coefficient of explanatory variables to be estimated.

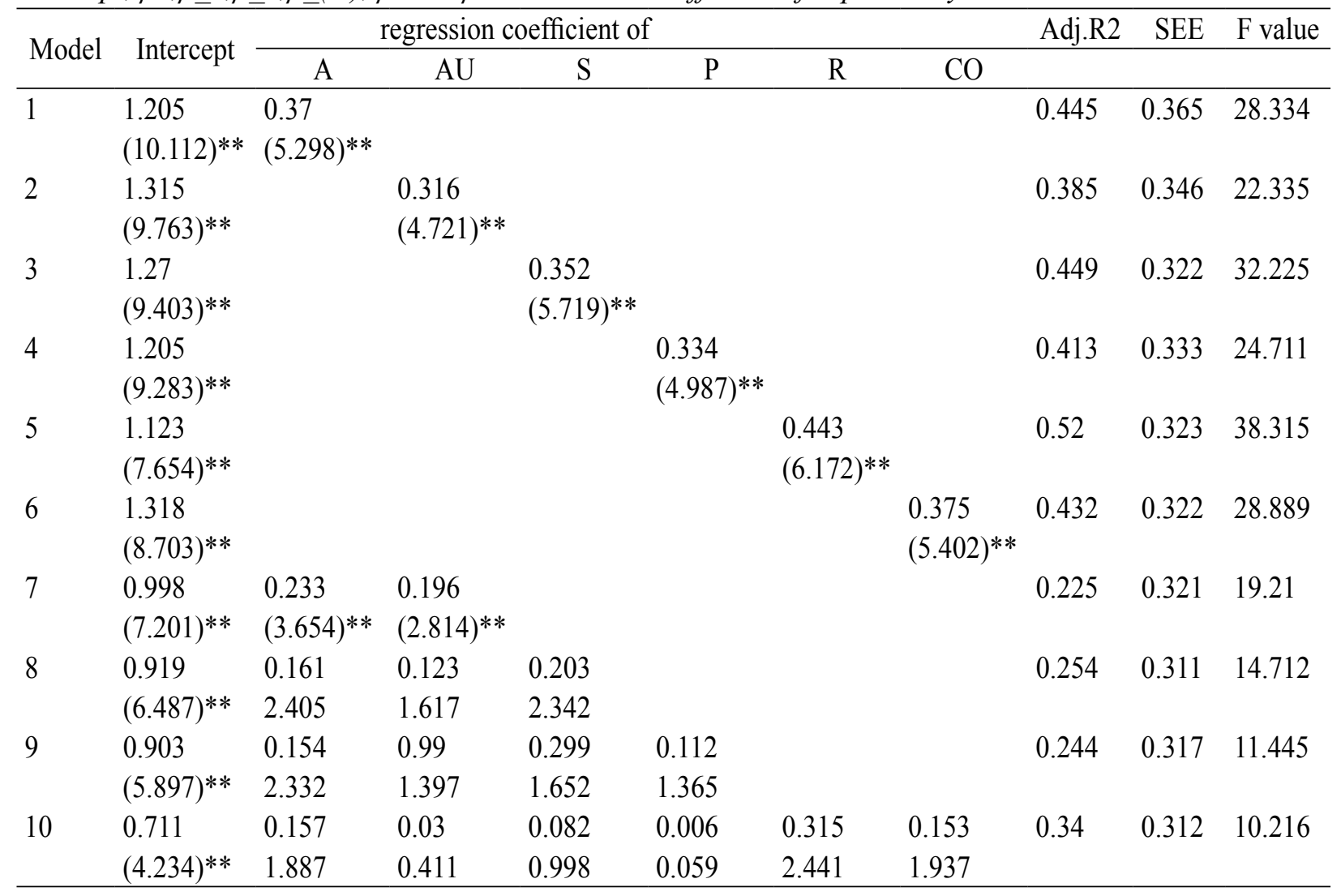


Notes:

Figures in parentheses are t-values.

The asterisk signs $\left({ }^{* *}\right)$ and $\left({ }^{*}\right)$ indicate that the results are significant at 1 percent and 5 percent level respectively.

The positive and significant beta for authority indicates that it has a positive impact on organizational citizenship behaviors and this result is similar to the findings of Shaaban (2018). Similarly, the beta coefficients are positive and significant for autonomy with organizational citizenship behaviors which states autonomy has a positive impact on organizational citizenship behaviors and this finding is consistent to Morgeson et al. (2005). Likewise, the positive and significant beta for salary reveals a positive impact on organizational citizenship behaviors and it is similar to the findings of (VansScotter, 2000). Additionally, the beta coefficients are positive and significant for a promotion that shows it has a positive impact on OCB and this result is consistent with the findings of Yaseen (2013).Furthermore, the beta coefficients are positive and significant for recognition with OCBthat indicates recognition has a positive impact on organizational citizenship behaviors and it is similar to the study of Sharma and Agrawal (2014).Moreover, the positive and significant beta for a career opportunity with OCB indicates that career opportunity impacts positive OCB. This result is consistent with the findings of Kraimer et al. (2011).

\section{Conclusion and Implications}

It is observed that most of the respondents believe that OCB is essential for motivation. All independent variables (authority, autonomy, salary, promotion, recognition, and career opportunity) are positively correlated with OCB that reveals these variables have a positive impact on organizational citizenship behavior. Hence, Nepalese non-life insurance companies should provide adequate authority, autonomy, promotion, sufficient salary, recognition, and career development opportunities to motivate the employees. Further studies can be conducted by considering other motivational factors like training and development, learning, love, points of rewards, belonging which affect the motivation on organizational citizenship behaviors.

\section{References}

Arshad, M., Abid, G., \& Torres, F. V. C. (2020). Impact of prosocial motivation on organizational citizenship behavior the mediating role of ethical leadership and leader-member exchange. Qual Quant,https:// doi.org/10.1007/s11135-020-00997-5

Bateman, T. S., \&Organ, D. W (1983).Job satisfaction and the good soldiers: The relationship between affect and employees citizenship. Academy of Management Journal, 26(4), 587-595.

Biswakarma, G.(2016). Organizational career growth and employees' turnover intentions: An empirical evidence from Nepalese private commercial banks. International Academic Journal of Organizational Behavior and Human Resource Management, 3, 10-26.

Castro, C. B., Armario, E. M., \& Ruiz, D. M. (2004).The influence of market heterogeneity on the relationship between a destinations image and tourists' future behavior. Tourism Management, 28(1), 175-187

Chiang, C. F., \& Hsieh, T. S. (2012). The impacts of perceived organizational support and psychological empowerment on job performance: The mediating effects of organizational citizenship behavior. International Journal of Hospitality Management, 31(1), 180-190.

Gagné, M. (2003). The role of autonomy support and autonomy orientation in prosocial behavior engagement. Motivation and Emotion, 27(3), 199-223.

Hieu, V. M., \& Cham, P. T. (2020). Examining the impact of the employee motivation factors on commitment in general insurance corporations in Ho Chi Minh City, Vietnam. International Journal of Psychosocial Rehabilitation, 24(07), 8435-8450.

Kim, S. H., Kim, M., \& Holland, S. (2019). Effects of intrinsic motivation on organizational citizenship behavior of hospitality employees: The mediating role of reciprocity and organizational commitment. 
Journal of Human Resources in Hospitality \& Tourism. 1-28. DOI: 10.1080/15332845.2020.1702866

Kraimer, M. L., Seibert, S. E., Wayne, S. J., Liden, R. C., \& Bravo, J. (2011). Antecedents and outcomes of organizational support for development: The critical role of career opportunities. Journal of Applied Psychology, 96(3), 485.

Meyer, J. P., Stanley, D.uences. J., Herscovitch, L., \&Topolnystky, L. (2002). Affective, continuance, and normative commitment to the organization: A meta-analysis of antecedents, correlates, and conses. Journal of Vocational Behavior, 61(1), 20-52.

Morgeson, F. P., Delaney-Klinger, K., \& Hemingway, M. A. (2005). The importance of job autonomy, cognitive ability, and job-related skill for predicting role breadth and job performance. Journal of Applied psychology, 90(2), 399.

Nam, K. S; \&Yoo, Y. J. (2016). The effects of fairness on abusive supervision and organizational citizenship behavior: Focusing on the Mediating on effect of Abusive Supervision. The Journal of the Korea Contents Association, 16,324-334.

Naway, F. A., \&Haris, I. (2017). The effect of career development, perception of organizational justice and job satisfaction on teacher's organizational citizenship behavior. International Review of Management and Marketing, 7(2), 17-21.

Nepal, P. (2016). Relationship between job satisfaction and performance of Nepalese commercial bank. Nepalese Journal of Management, 3(3), 41-50.

Newburry, W., Belkin, L. Y., \& Ansari, P. (2008). Perceived career opportunities from globalization: Globalization capabilities and attitudes towards women in Iran and the US. Journal of International Business Studies, 39(5), 814-832.

Pujiwati, A. (2016). The influence of performance assessment andcareer development on employee's commitment. Review of Integrative Business and Economics Research, 5(2), 175-185.

Shaaban, S. (2018). The impact of motivation on organizational citizenship behavior (OCB): The mediation effect of employees' engagement. Journal of Human Resource Management, 6(2), 58-66.

Sharma, S. K., \& Agrawal, S. (2014). A study of antecedents and consequents of organizational citizenship behavior through causal loop diagram: A holistic approach. IUP Journal of Organizational Behavior, $13(3), 7-20$.

Sinnappan, L. P., \&Amulraj, M. (2014). Impact of rewards and recognition and empowerment on organizational citizenship behaviors among technical engineers. Management Studies and Economic Systems, 54(13), 1-7.

Vans Scotter, J. R. (2000). Relationships of task performance and contextual performance with turnover, job satisfaction, and affective commitment. Human Resource Management Review, 10(1), 79-95.

Yaseen, A. (2013). Effect of compensation factors on employee satisfaction -a study of doctor's dissatisfaction in Punjab. International Journal of Human Resources Studies, 3(1), 142-157. 